April 2017

\title{
Conflict in South Asia and its impact on health
}

Siddarth David

School of Habitat Studies, Tata Institute of Social Sciences, Mumbai, India

Rukhsana Gazi

Centre for Equity and Health Systems, International Centre for Diarrheal Research, Dhaka, Bangladesh

Mohammed Shafiq Mirzazada

Aga Khan Health Service, Kabul, Afghanistan, shafiq.mirzazada@aku.edu

Chesmal Siriwardhana

THEME Institute, Colombo, Sri Lanka

Sajid Bashir Soofi

Agha Khan University, sajid.soofi@aku.edu

See next page for additional authors

Follow this and additional works at: https://ecommons.aku.edu/ pakistan_fhs_mc_women_childhealth_paediatr

Part of the Psychiatric and Mental Health Commons, and the Public Health Commons

\section{Recommended Citation}

David, S., Gazi, R., Mirzazada, M. S., Siriwardhana, C., Soofi, S., Roy, N. (2017). Conflict in South Asia and its impact on health. BMJ, 357(j1537), 1-5.

Available at: https://ecommons.aku.edu/pakistan_fhs_mc_women_childhealth_paediatr/366 
Authors

Siddarth David, Rukhsana Gazi, Mohammed Shafiq Mirzazada, Chesmal Siriwardhana, Sajid Bashir Soofi, and Nobhojit Roy 


\title{
Conflict in South Asia and its impact on health
}

\author{
Improving access to healthcare, preventing gender based violence, and providing mental \\ health services are essential to improve the health of people affected by conflict in South Asia, \\ argue Siddarth David and colleagues
}

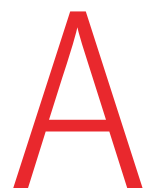

ccording to the Uppsala Conflict Data Program (UCDP), a conflict is a contested incompatibility that concerns government, territory, or both, in which the use of armed force between two parties, of which at least one is the government of a state, results in at least 25 battle related deaths. Low intensity conflicts such as insurgencies, counterinsurgencies, civil strife, terrorism, and communal riots have taken the place of large conventional battles across the world. Such conflicts tend to continue at low levels for a long period of time with sporadic outbursts. Moreover, these protracted low intensity conflicts result in prolonged displacement, cross border migration, and trafficking. Most affected populations are unable to access existing healthcare services owing to lack of documentation, means of livelihood, and social capital. ${ }^{1}$ Public health aspects such as nutrition, water, and sanitation are also severely affected. Healthcare services are often suspended, withdrawn, or rendered impossible, posing a huge health burden compounded by the health needs of displaced populations. ${ }^{2}$

Research has shown how protracted conflicts can affect specific health outcomes

\section{KEY MESSAGES}

South Asia has a large population affected by different types of protracted conflict and can provide critical insights to understand health challenges in conflict zones

Health systems in conflict affected areas should prioritise domestic and gender based violence, along with reproductive and sexual health services

Mental health and psychosocial services for conflict affected populations in South Asia need to be strengthened, and these services should be integrated into existing primary care platforms

Building the capacity of the existing healthcare system and developing a trained local workforce can improve the access to and availability and acceptability of health services in conflict affected communities

Research capability must also be strengthened for mutual learning and regional collaborations to develop context specific solutions throughout South Asia influenced by impediments to accessing healthcare services, pressures on health systems, burden of unmet health needs, and attacks on health facilities and service providers. ${ }^{2-10}$ However, lessons have been also learnt, strategies devised, and innovations created to meet the challenges to health in conflict situations. ${ }^{11} 12$

South Asia, with its shared cultural and geopolitical history, is home to several protracted conflicts both within and between countries (box 1). The countries also share similar developmental, social, and health challenges and have been attempting to foster regional cooperation through associations such as the South Asian Association for Regional Cooperation (SAARC), albeit not in tackling conflict related problems. Home to a fifth of the world's population, the region has a history of protracted conflict and can offer critical insights into understanding the impact of conflicts on health. This, in turn, can help in identifying solutions, tracking innovations, and advocating changes to policy and practice that enable organisations and governments to respond better. ${ }^{23}$ In this paper, we highlight some of the key health consequences and responses in conflict affected areas of South Asian countries and recommend key actions for the future.

\section{Impact on key aspects of health} Mortality and morbidity

Given the different types, length, and intensity of conflicts in South Asia, estimating the overall number of casualties is difficult. Estimates from databases show 333436 direct deaths due to conflict in the region since the $1980 \mathrm{~s},{ }^{14}$ although given the limited data collected on deaths due to conflicts, these figures could be underestimates. ${ }^{24}$ Of these, more than a third of the deaths are of civilians. ${ }^{25}$ Conflict in the region has also resulted in large numbers of indirect deaths, due to the collapsed health systems, which are difficult to record but represent a crucial mortality burden. ${ }^{26}$ Data on injury are harder to determine, although evidence from Afghanistan and Pakistan indicates that the injured outnumber the dead. ${ }^{27}$ Health facility based studies from the region indicate that with gunshots and bomb explosions contributing to most of the violent trauma, survivors need extensive rehabilitation services, which are mostly unavailable and difficult to provide. ${ }^{2829}$

\section{Women's and children's health}

During armed conflicts, gender based crimes and violence become more frequent, with forced abduction or sexual violence. ${ }^{3031}$ Also, women experience unequal access to services such as healthcare when men control access to services and goods. ${ }^{3032}$ Studies from Afghanistan show that protracted conflicts also augment the risk of childhood morbidity and mortality owing to increased exposure to infectious diseases and unsanitary living conditions and destruction of health facilities. ${ }^{33}$ The combination of displacement, poverty, infectious diseases, and lower food production may cause these children to experience food insecurity, malnutrition, physical (stunting and wasting) and diarrhoeal diseases, acute respiratory infections, and psychological problems (anxiety, depression, and post-traumatic stress disorder). ${ }^{303334}$

Research from Pakistan and Bangladesh shows that the culture of child marriage in the region is exacerbated in conflict areas, along with maternal malnourishment and sexually transmitted diseases, increasing the risk of maternal and child deaths. ${ }^{35}$ Studies from Bangladesh indicate that women with lower levels of education, scant sources of income, limited mobility, and a smaller role in decision making are at the greatest risk of intimate partner violence. ${ }^{36-38}$ All of these are common among displaced populations and against the backdrop of protracted conflicts and camp situations with breakdown of family and community safety structures. Prevailing insecurity means that enforcing any existing laws on protecting women from violence is a challenge.

\section{Mental health}

The effect on mental health of protracted conflict and prolonged internal/external displacement in the region is extensive and compounded by large scale natural disasters such as the 2004 Indian Ocean tsunami, 2005 Pakistani earthquake, and 2015 earthquake in Nepal. The number of people in South Asia with mental illness was approximately 200 million in 2006,,$^{39}$ and it is predicted to rise..$^{40}$ Although region-wide 


\section{Box 1: Conflicts in selected countries of South Asia}

\section{Afghanistan}

Decades of conflict have had a devastating impact on health in Afghanistan. ${ }^{13} \mathrm{~A}$ few years of partial stability and development followed the fall of the Taliban. However, violence has been increasing, leading to a rise in insecurity and consequent incapacitation of health services. ${ }^{14}$

\section{Bangladesh}

Two types of conflict related displaced populations are present in Bangladesh: Rohingyas (a stateless group from Myanmar) and Biharis (non-Bengali citizens living in refugees camps since the war of 1971). Both these groups are deprived of access to the national healthcare system and proper sanitation facilities and exposed to high risk sexual behaviour and hazardous health conditions. ${ }^{115}$

\section{India}

With diverse ethnic, linguistic, and religious groups, parts of India have low intensity and protracted conflict. Three major zones of conflict are the state of Jammu and Kashmir, insurgency in some of the states in the remote north east, and the Maoist insurgency (Naxalite) in parts of central India. ${ }^{16}$ Violence by armed groups, counter-insurgency operations, and internal displacement have crippled the healthcare services through chronic disruptions.

\section{Nepal}

The Communist Party of Nepal (Maoist) led an armed insurgency against the Nepali state in 1996, resulting in a civil conflict that lasted for a decade and claimed more than 13000 lives. ${ }^{17}$ This conflict led to population displacements and destruction of healthcare facilities and affected the already weak health system. ${ }^{18}$

\section{Pakistan}

As a result of multiple large influxes since 1979, Pakistan has hosted a vast number of Afghan refugees, burdening the already resource constrained public health delivery systems. ${ }^{19} 20$ Furthermore, in 2015, more than 1.1 million people became internally displaced because of repeated military operations and sectarian violence in the Federally Administered Tribal Areas. ${ }^{21}$ These internal conflicts have caused substantial damage to health facilities and services in the area. ${ }^{22}$

\section{Sri Lanka}

Since independence, Sri Lanka has experienced violence from leftist insurgencies in the south and protracted conflict in the north and east that ended in 2009. Thousands have died or become injured, disabled, and displaced as a result. The health impact of conflict still cannot be fully measured, although health services have significantly improved in post-conflict regions. ${ }^{9}$

figures are not available, country specific evidence suggests high levels of mental disorders directly attributed to conflict across South Asia. Mental disorders most commonly attributed to conflict in the region are depression, anxiety, and post-traumatic stress disorder, with variations across countries (table 1). ${ }^{941} 42$

These variations may be influenced by factors such as the nature of the conflict (ethnic, religious, ideological), its duration (acute, protracted, recurrent), the region (urban, rural), and forced displacement. However, higher prevalence of mental disorder shows a host of similar sociodemographic associations across countries such as older age, female sex, displacement, being widowed/divorced, low income/education, and food insecurity. Despite the higher burden, the mental health treatment gap for conflict affected populations across South Asia is extensive, as a result of non-prioritisation of psychosocial health, stigma, lack of specialists, and lack of integration with primary care. The median allocation of health budget for mental health was $0.44 \%$ in the World Health Organization SEARO region in 2016, compared with a world median of $2.82 \% .43$

\section{Health costs}

The costs of conflict in South Asia have had an impact on individuals, countries, and health systems in multiple ways. Firstly, the number of people affected by conflict is increasing, leading to increased mortality and morbidity and increased pressure on existing health systems to respond. This is compounded by diversion of public health finances for military requirements and weakening of existing health systems due to lack of funding and conflict related violence. Secondly, the cost of obtaining healthcare for people affected by conflict, especially refugees and internally displaced people, is increasing as a result of breakdown of primary healthcare systems and a lack of human resources, medical supplies, and access. Thirdly, the region's historical under-investment in healthcare has resulted in weak health systems that require significant costs for maintenance and upgrading,
Table 1 | Prevalence (\%) of mental health disorder attributed to conflict in select countries in South Asia9 ${ }^{4142}$

\begin{tabular}{llll} 
Country & Depression & Anxiety & Post-traumatic stress disorder \\
Afghanistan & $38-68$ & $52-72$ & $20-42$ \\
\hline Nepal & 27 & 23 & 10 \\
\hline Sri Lanka & $5-30$ & $2-40$ & $2-27$
\end{tabular}

especially during times of conflict. Sri Lanka may be the only exception in the region, although recent evidence suggests that the cost of protracted conflict in the country has taken a heavy toll on its public health system. ${ }^{44}$

\section{Health impact over time}

The effects of conflict over time on the health of affected South Asian populations are manifold. Evidence from Sri Lanka shows an increased risk of infectious diseases such as tuberculosis, polio, malaria, and diarrhoeal diseases; increased war related physical injuries and disability; child health problems such as malnutrition, developmental disorders, and infections; reproductive health disorders and gender based/interpersonal violence; and increased numbers of children and adults with war related mental health problems. ${ }^{9}$ Some South Asian countries such as Pakistan and Afghanistan continue to experience chronic conflict, and others such as Nepal and Sri Lanka are yet to recover fully from the lingering effects of protracted conflict on the health of their populations.

\section{Terrorism}

In the past decade, South Asia has seen a distinct rise in the number of terrorist activities, violence, and deaths. Although the number of lives claimed by terrorists is relatively small, the consequent fear in 
populations after they witness reports in the media of deliberate and destructive acts is disproportionately large. The most densely populated cities in the world are in this region and are the usual targets for terrorist activities and the threat of use of chemical and biological materials. The other damaging effect is on a city's trade and financial markets. Explosives and small arms remain the most common weaponry and more recently are combined with arson and hostage taking. ${ }^{45}$ The growing nuclear capability in the region makes the use of nuclear weapons an important concern, despite governments claiming a no first use policy. The aetiology of terrorism leading to this fragile security situation is complex, with non-resolution of core disputes, uneven development, social injustice, calls for revenge, poverty, and exploitation in the region. Political solutions are more likely to be successful than military ones in conflict resolution.

\section{Access barriers}

Multiple barriers to access to healthcare for conflict affected populations are common across the region. Some of these barriers are similar to those in other global regions such as the Middle East, Africa, or South America, whereas others are unique to South Asia. For example, weak health systems, rural populations, and lack of adequate human resources, financial resources, and political will are barriers commonly found across South Asia and other parts of the world. Displaced populations have no formal linkages to existing health facilities and are often at risk of being discriminated against and abused, compelling them to obtain services from informal providers who may be unqualified and offer services that are of substandard quality. ${ }^{4647}$ Problems with access due to geographical limitations, weak transportation links/systems, rapid urbanisation, growing economic inequalities, and historical cultural/language/religious mistrust are some of the more specific factors that hinder adequate access to healthcare for conflict affected populations in South Asia. ${ }^{46-49}$ These factors combine to create significant disparity in how services are accessed by different population groups.

For example, Sri Lanka, despite having developed a robust public health system, still has a significant gap in mental healthcare provision to post-conflict populations owing to the lack of integration of mental health into the primary care system. ${ }^{9}$ In 2002, after three decades of conflict that devastated the public health system, Afghanistan's maternal mortality ratio, under-5 mortality, and infant mortality rates were 1600/100000 live births, 257/1000 live births, and 167/1000 live births, respectively. However, after the introduction of a basic package of health services and an essential package of hospital services by the Ministry of Public Health of Afghanistan, with support from the international community, access to health services and health indicators in the country have improved significantly, reflected in the results of the recent Afghanistan mortality survey. ${ }^{50}$

\section{Innovations and initiatives}

With such a wide array of health challenges, resource limitations, and a range of stakeholders, any attempt to tackle these health problems would require contextual strategies, combined efforts of multiple partners, and different approaches. It is important, therefore, to explore such endeavours in the region, however few or small they may be, as they could offer insights and lessons relating to the health problems raised above in different conflict affected areas in the regions, as well as ways to improve existing capacities.

\section{Role of government and international humanitarian organisations}

Governments and international organisations have played a significant role in improving the health of conflict affected people in the region. For example, the Sri Lankan government has, with the support of international agencies, invested significant financial resources in the health infrastructure of post-conflict areas. ${ }^{9}$ In Nepal, non-governmental organisations including international humanitarian organisations have significantly contributed to improve psychosocial services for post-conflict populations. ${ }^{51}$ Health service delivery in some provinces of Afghanistan has been contracted out to national and international organisations and is seen as an effective way to expand services to remote and insecure areas. ${ }^{11}$ International medical organisations such as Médicins Sans Frontières have joined the government to offer emergency medical care including mental health services in conflict affected regions of Pakistan. ${ }^{52}$

However, a lack of public-private partnerships is common across the region, and a lot of work by non-governmental organisations and international humanitarian organisations is conducted in isolation. Despite the common problems and experiences with conflicts, displaced populations, and provision of healthcare, regional initiatives attempting to find common solutions are scarce. Governments of South Asian countries need to lead sustained attempts to learn from the experiences and expertise of neighbouring countries to manage conflict related health problems of their populations. Regional intergovernmental bodies such as SAARC should lead the mobilisation of health professionals, academics, and researchers to find regional health solutions for conflict affected populations in South Asia.

\section{Capacity building of healthcare providers} to serve in areas of conflict

Enhancing the capacity of healthcare providers, particularly through reconstructing and strengthening health infrastructure in conflict affected areas, is a priority. ${ }^{5354}$ Strategic placement of effective leaders in health institutions is needed to ensure effective service delivery and an accelerated development of health infrastructure. ${ }^{53}$ Furthermore, provision of targeted training sessions combined with performance linked incentives is needed to entice motivated staff to conflict areas.

The initiative in Afghanistan, involving training community midwives and nurses from local communities through a two year programme, with a bond to work in facilities located in their villages, played a major role in ensuring availability of skilled female health workers in remote and insecure areas. ${ }^{55}$ This is underscored by the fact that there were only 467 midwives in Afghanistan in 2002 and there were more than 4500 working midwives in 2014. ${ }^{56}$ These trained midwives and nurses are locally accepted and have played an important role in improving maternal and child health indicators. ${ }^{55}$

\section{Research capability}

Although there are country specific initiatives to tackle health outcomes related to conflict in the region, huge scope exists for more research, to understand the needs of conflict affected population and identify possible solutions to them. Additionally, any health research conducted in conflict zones should adhere strictly to ethical guidelines, especially posing minimal harm and preventing re-traumatisation. Creating consortiums of public health researchers, experts, and administrators from the region to collaborate in building evidence of challenges, lessons learnt, strategies, and innovations would be an important step to tackle some of these problems. The outputs of such platforms can shape better policies and practices to improve and expand health interventions in conflict areas.

\section{Conclusion}

This paper has attempted to map the broader cross cutting problems related to 
protracted conflict and health in the South Asia region by exploring a range of matters such as mortality, sexual health, mental health, costs, access, and innovations in the regional context. There is a need to focus on reproductive and child health, including gender based violence, mental health services, local innovations, and trained workforces in conflict affected areas to improve health outcomes. A huge opportunity also exists for mutual learning, regional collaborations, and enhancing research capabilities to improve access to healthcare and the capacity of existing healthcare systems to meet the health needs of conflict affected areas. This will enable development of context specific solutions that can tackle health concerns related to conflict zones in South Asia and may offer lessons for the rest of the world.

Contributors: SD was involved in writing, editing, and developing the structure of the paper. RG, MSM, and SS were involved in writing the paper. CS was involved in writing and editing the paper. NR developed the structure of the paper and was involved in writing and editing it.

Competing interests: We have read and understood BMJ policy on declaration of interests and have no relevant interests to declare.

Provenance and peer review: Commissioned; externally peer reviewed.

Siddarth David, senior research officer 1,2

Rukhsana Gazi, former scientist ${ }^{3}$

Mohammed Shafiq Mirzazada, chief executive officer founding member 4,5

Chesmal Siriwardhana, founder member associate professor in global mental health 6,7

Sajid Soofi, associate professor and consultant paediatrician $^{8}$

Nobhojit Roy, public health specialist professor of surgery honorary research fellow', 1,10

'School of Habitat Studies, Tata Institute of Social Sciences, Mumbai, India

${ }^{2}$ Implementing Lancet Commission on Global Surgery in India, India

${ }^{3}$ Centre for Equity and Health Systems, International Centre for Diarrheal Research, Dhaka, Bangladesh

${ }^{4}$ Aga Khan Health Service, Kabul, Afghanistan

${ }^{5}$ Afghanistan National Public Health Association, Kabul, Afghanistan

6THEME Institute, Colombo, Sri Lanka

${ }^{7}$ Department of Population Health, London School of Hygiene and Tropical Medicine, London, UK

${ }^{8}$ Aga Khan University, Karachi, Pakistan

'BARC Hospital, HBNI University, Mumbai, India

${ }^{10}$ Humanitarian Conflict Research Institute, University of Manchester, Manchester, UK

Correspondence to: S David siddarthdavid@yahoo. co.in

Gazi R, Mercer A, Wansom T, Kabir H, Saha NC, Azim T. An assessment of vulnerability to HIV infection of boatmen in Teknaf, Bangladesh. Confl Health 2008:2:5. doi:10.1186/1752-1505-2-5.

2 International Committee of the Red Cross. Health care in danger: a sixteen-country study. In: Book Health care in danger: a sixteen-country study. International Committee of the Red Cross, 2011:2-3.

3 Khanday Z. Negotiating reproductive health needs in a conflict situation in the Kashmir Valley.Achutha Menon Centre for Health Science Studies, Sree Chitra Institute of Medical Sciences and Technology, 2005. de Jong K, Kam Sv, Ford N, et al. Conflict in the Indian Kashmir Valley II: psychosocial impact. Confl Health 2008;2:11. doi:10.1186/1752-1505-2-11.

Dye S, Bishai L. Public health and conflict in Iraq: rebuilding a nation's health. 2007. https://www.usip. org/sites/default/files/public_health_iraq.pdf.

6 Thomas FC, Roberts B, Luitel NP, Upadhaya N, Tol WA Resilience of refugees displaced in the developing world: a qualitative analysis of strengths and struggles of urban refugees in Nepal. Confl Health 2011;5:20 doi:10.1186/1752-1505-5-20

Al Hilfi TK, Lafta R, Burnham G. Health services in Iraq Lancet 2013:381:939-48, doi:10.1016/

S0140-6736(13)60320-7.

8 Sinha S, David S, Gerdin M, Roy N. Vulnerabilities of local healthcare providers in complex emergencies: findings from the Manipur Micro-level Insurgency Database 2008-2009. PLoS Curr 2013;5:5

9 Siriwardhana C, Wickramage K. Conflict, forced displacement and health in Sri Lanka: a review of the research landscape. Confl Health 2014;8:22. doi:10.1186/1752-1505-8-22

10 Pérous de Montclos M, Minor E, Sinha S, eds Violence, statistics, and the politics of accounting for the dead.Springer, 2016doi:10.1007/978-3-31912036-2.

11 Rahimzai M, Naeem AJ, Holschnieder S, Hekmai AK. Engaging frontline health providers in improving the quality of health care using facility-based improvement collaboratives in Afghanistan: case study. Confl Health 2014:8:21doi:10.1186/1752-1505-8-21.

12 Rowe JS, Natiq K, Alonge O, Gupta S, Agarwal A, Peters $\mathrm{DH}$. Evaluating the use of locally-based health facility assessments in Afghanistan: a pilot study of a novel research method. Confl Health 2014:8:24. doi:10.1186/1752-1505-8-24

13 Acerra JR, Iskyan K, Qureshi ZA, Sharma RK. Rebuilding the health care system in Afghanistan: an overview of primary care and emergency services. Int I Emerg Med 2009;2:77-82. doi:10.1007/s12245-009-0106-y.

14 Uppsala Conflict Data Program. Number of deaths: Afghanistan, Bangladesh, India, Nepal, Pakistan and Sri Lanka 1975-2015. 2016. http://ucdp.uu.se/.

15 Danish Immigration Services. Rohingya refugees in Bangladesh and Thailand. Bangkok: fact finding mission to Bangladesh and Thailand. Danish Immigration Services. 2011. https://www.nyidanmark dk/NR/rdonlyres/B08D8B44-5322-4C2F-960444F6C340167A/0/FactfindingrapportRohingya 180411.pdf.

16 Ranvijay. Violent conflict in India: issues of contention. 2010. http://www.monitor.upeace.org/innerpg cfm?id article $=685$.

17 United Nations Office of the High Commissioner for Human Rights (UNOHCHR). Nepal conflict report. 2012 http://www.ohchr.org/Documents/Countries/NP/ OHCHR_Nepal_Conflict Report2012.pdf.

18 Devkota B, van Teijlingen ER. Understanding effects of armed conflict on health outcomes: the case of Nepal. Confl Health 2010;4:20. doi:10.1186/1752-1505-4-20.

19 Refugee Affected and Hosting Areas Programme (RAHA). RAHA brochure Pakistan. 2016. http:// unhcrpk.org/wp-content/uploads/2013/12/ RAHA-Brochure-June-20161.pdf

20 United Nations High Commission for Refugees (UNHCR). UNHCR regional plan: building resilience and solutions for Afghan refugees in South-West Asia. 2016. http://unhcrpk.org/wp-content/ uploads/2013/12/UNHCR-Regional-Plan-Resilienceand-Solutions-for-Afghan-refugees-in-South-WestAsia1.pdf.

21 United Nations High Commission for Refugees (UNHCR) Pakistan. 2015-2017 protection strategy. 2015. http://unhcrpk.org/contacts/fact-sheets/.

22 Federally Administered Tribal Areas Secretariat. FATA sustainable return and rehabilitation strategy. 2015 http://www.pk.undp.org/content/pakistan/en/home/ library/crisis_prevention_and_recovery/ fata-sustainable-return-and-rehabilitation-strategy-/.

23 Ghani E, Iyer L. Conflict and development - lessons from South Asia. Economic Premise No 31. 2010. http://siteresources.worldbank.org/INTPREMNET/ Resources/EP31.pdf.

24 Gleditsch NP, Wallensteen P, Eriksson M, Sollenberg M, Strand H. Armed conflict 1946-2002, a new dataset. J Peace Res

2002;39:615-37doi:10.1177/0022343302039005007.

25 South Asia Terrorism Portal. South Asia fatalities 2005-2017. 2017. http://www.satp.org/satporgtp/ southasia/datasheets/Fatalities.html.
26 Murray CJ, King G, Lopez AD, Tomijima N, Krug EG. Armed conflict as a public health problem. BMJ 2002;324:346-9. doi:10.1136/bmj.324.7333.346.

27 Crawford N. War-related death, injury, and displacement in Afghanistan and Pakistan 2001-2014. 2015. http://watson.brown.edu/costsofwar/files/cow/ imce/papers/2015/War\%20Related\%20 Casualties\%20Afghanistan\%20and\%20Pakistan\%20 2001-2014\%20FIN.pdf.

28 Valles P, Van den Bergh R, van den Boogaard W, et al. Emergency department care for trauma patients in settings of active conflict versus urban violence: all of the same calibre? Int Health 2016;8:390-7. doi:10.1093/inthealth/ihw035.

29 Gohy B, Ali E, Van den Bergh R, et al. Early physical and functional rehabilitation of trauma patients in the Médecins Sans Frontières trauma centre in Kunduz, Afghanistan: luxury or necessity?!nt Health 2016;8:381-9. doi:10.1093/inthealth/ihw039.

30 Eyber C. Children in situations of armed conflict. 2011. http://www.forcedmigration.org/research-resources/ expert-guides/psychosocial-issues/ children-in-situations-of-armed-conflict.

31 Goetz AM, Treiber AK. Gender and conflict analysis.2nd ed. UN Women, 2012

32 OXFAM. Gender issues in conflict and humanitarian action. 2013. https://www.oxfam.org/sites/www. oxfam.org/files/hpn-gender-conflict-humanitarianaction-291113-en.pdf.

33 Tamashiro T. The hidden crisis: armed conflict and education. 2011. http://unesdoc.unesco.org/ images/0019/001907/190712e.pdf.

34 Rieder M, Choonara I. Armed conflict and child health. Arch Dis Child 2012;97:59-62. doi:10.1136/ adc. 2009.178186

35 Plan International. Getting the evidence: Asia child marriage initiative. 2015. https://plan-international. org/publications/ getting-evidence-asia-child-marriage-initiative\#

36 Naved RT, Persson LA. Factors associated with physical spousal abuse of women during pregnancy in Bangladesh. Int Fam Plan Perspect 2008:34:71-8. doi:10.1363/3407108

37 Sambisa W, Angeles G, Lance PM, Naved RT, Thornton J. Prevalence and correlates of physical spousal violence against women in slum and nonslum areas of urban Bangladesh / Interpers Violence 2011:26.2592 618. doi:10.1177/0886260510388282.

38 VanderEnde KE, Sibley LM, Cheong YF, Naved RT, Yount KM. Community economic status and intimate partner violence against women in bangladesh: compositional or contextual effects?Violence Against Women 2015;21:679-99. doi:10.1177/1077801215576938

39 Thara R, Padmavati R. Community mental health care in South Asia. World Psychiatry 2013;12:176-7. doi:10.1002/wps.20042.

40 Shidhaye R, Sikander S, Jordans M, De Silva P, Chatterjee S. Mental health programs and policies in South Asia: initiatives and obstacles. In: Trivedi JK, Tripathi A, eds. Mental health in South Asia: ethics, resources, programs and legislation.Springer Netherlands, 2015 : 95-111doi:10.1007/978-94-017-9017-8_7.

41 Luitel NP, Jordans MJ, Sapkota RP, et al. Conflict and mental health: a cross-sectional epidemiological study in Nepal. Soc Psychiatry Psychiatr Epidemiol 2013;48:183-93. doi:10.1007/s00127-012-0539-0.

42 Murthy RS, Lakshminarayana R. Mental health consequences of war: a brief review of research findings. World Psychiatry 2006;5:25-30.

43 World Health Organization. Pakistan: Health system strengthening. 2016. http://www.emro.who.int/pak/ programmes/health-system-strengthening-hss.html.

44 Johnson SA. The cost of war on public health: an exploratory method for understanding the impact of conflict on public health in Sri Lanka. PLoS One 2017;12:e0166674. doi:10.1371/journal. pone.0166674.

45 Roy N, Kapil V, Subbarao I, Ashkenazi I. Mass casualty response in the 2008 Mumbai terrorist attacks. Disaster Med Public Health Prep 2011;5:273-9. doi:10.1001/dmp.2011.80.

46 Chatterjee M, Levine R, Rao-Seshadri S, Murthy N. Sparing lives: better reproductive health for poor women in South Asia. 2007. https://openknowledge. worldbank.org/handle/10986/7667.

47 Thin Zaw PP, Liabsuetrakul T, Htay TT, McNeil E. Equity of access to reproductive health services among youths in resource-limited suburban communities of Mandalay City, Myanmar. BMC Health Serv Res 2012;12:458. doi:10.1186/1472-6963-12-458. 
48 Jacobs B, Ir P, Bigdeli M, Annear PL, Van Damme W. Addressing access barriers to health services: an analytical framework for selecting appropriate interventions in low-income Asian countries. Health Policy Plan 2012;27:288-300. doi:10.1093/heapol/ czr038.

49 Howarth LA, Walker JJ. The role of family planning in South Asia. BJOG 2011;118(Suppl 2):31-5. doi:10.1111/i.1471-0528.2011.03110x.

50 Afghan Public Health Institute, Ministry of Public Health (APHI/MoPH), Central Statistics Organization (CSO), ICF Macro, Indian Institute of Health Management Research (IIHMR), World Health Organization Regional Office for the Eastern Mediterranean (WHO/EMRO). Afghanistan mortality survey 2010. APHI/MoPH, CSO, ICF Macro, IIHMR, WHO/EMRO, 2011 (available from http://dhsprogram.com/pubs/ pdf/fr248/fr248.pdf).
51 Upadhaya N, Luitel N, Koirala S, et al. The role of mental health and psychosocial support in nongovernmental organisations: reflections from postconflict Nepal. Intervention (Amstelveen) 2014:12:113-28doi:10.1097/ WTF.0000000000000064

52 Shah S, Van den Bergh R, Van Bellinghen B, et al. Offering mental health services in a conflict affected region of Pakistan: who comes, and why?PLoS One 2014;9:e97939. doi:10.1371/journal.pone.0097939.

53 McKechnie AJ. Building capacity in post-conflict countries. 2004. http://siteresources.worldbank.org/ INTCDRC/Resources/CDBrief05.pdf.

54 United Nations Department of Economic and Social Affairs. Building capacities for public service in post-conflict countries. UN, 2007 (available from https://publicadministration.un.org/publications/ content/PDFs/E-Library\%20Archives/2007\%20 Building\%20Capacities\%20for\%20Public\%20 Service\%20in\%20Post\%20Conflict\%20Countries.pdf).
55 Mohmand KA. Community midwifery education program in Afghanistan. 2013. http://documents. worldbank.org/curated/en/138781468185951486/ Community-midwifery-education-program-inAfghanistan.

56 Raja F. State of Afghanistan's midwifery 2014. United Nations Population Fund, 2014 (available from https:// countryoffice.unfpa.org/filemanager/files/ afghanistan/2014/reports/midwifery_report_2014 english.pdf).

Cite this as: $B M J$ 2017;357:j1537

http://dx.doi.org/10.1136/bmj.j1537 